\title{
Effects and interactions of temperature, host deprivation and adult feeding on the longevity of the parasitoid Venturia canescens (Hymenoptera: Ichneumonidae)
}

\author{
Panagiotis A. ELIOPOULOS ${ }^{1}$, George J. STATHAS ${ }^{2 *}$ and Stelios L. BOURAS ${ }^{1}$ \\ ${ }^{1}$ Agricultural University of Athens, Faculty of Plant Production, Laboratory of Agricultural Zoology and Entomology, \\ 75 Iera Odos Str, 11855 Votanikos, Athens, Greece; e-mail: p_eliopoulos@hotmail.com \\ ${ }^{2}$ Laboratory of Biological Control, Benaki Phytopathological Institute, 8 St. Delta Str., 14561 Kifissia, Athens, Greece
}

Key words. Venturia canescens, longevity, parasitoid, adult feeding, temperature, host deprivation, body size

\begin{abstract}
A laboratory study was carried out to determine the effects and interactions of temperature, host deprivation and adult feeding on the longevity of the parasitoid Venturia canescens (Gravenhorst) (Hymenoptera: Ichneumonidae). The effect of body size was also examined. Large wasps (hind tibia length $>1.96 \mathrm{~mm}$ ) lived significantly longer than smaller conspecifics (hind tibia length $<1.89 \mathrm{~mm}$ ). Adults reared at $15^{\circ} \mathrm{C}$ lived longer regardless of whether supplied with hosts or food. Correspondingly, adults had a shorter life at $30^{\circ} \mathrm{C}$. Honey-fed adults lived significantly longer than starved adults at all temperatures and irrespective of host presence, while access to hosts resulted in a decrease in longevity at all temperatures, regardless of food supply. The Weibull distribution was used to describe the age specific survival, which in $V$. canescens is of "Type I", as the risk of death increases with age. Despite the significant effect of host presence on survival it was less than either temperature or feeding. The interactions between feeding, host presence and temperature proved to be significant. The objective of the study was to improve the effectiveness of $V$. canescens as a biological control agent of stored product pests.
\end{abstract}

\section{INTRODUCTION}

Adult longevity is an important factor in the population dynamics of parasitoids and influences their effectiveness in exploiting host populations. The longer a male wasp lives the more females it can inseminate, while the longer a female can live the more eggs it can lay (Tingle \& Copland, 1989; Jervis \& Copland, 1996; Jervis et al., 1996). Longevity is a variable species specific characteristic, which is influenced by a range of biotic (host, body size, mating, adult feeding, etc.) and abiotic (temperature, humidity, photoperiod) factors (Jervis \& Copland, 1996).

The present study deals with the effect of some of the above factors on the longevity of Venturia canescens (Gravenhorst) (Hymenoptera: Ichneumonidae), a thelytokous, koinobiont, solitary, endoparasitoid of lepidopterous larvae. Its host range includes many moth species, mainly pyralids attacking stored products (Frilli, 1965; Salt, 1975, 1976). The influence of adult feeding, host presence and temperature on the longevity of $V$. canescens has been well studied (Candura, 1928; Beling, 1932; Ahmad, 1936; Frilli, 1965; Kurstak, 1966; Shikrenov, 1970; Matsumoto, 1974). However, the use of variable temperatures and different types of adult food has resulted in contradictory results. In addition, it is unknown whether interactions between these factors affect the longevity of $V$. canescens.

In the present study, the effect of biotic (body size, presence of adult food and / or host) and abiotic (temperature) factors on the longevity and survival of $V$. canescens was examined. The interactions among those factors on the longevity of $V$. canescens were also analyzed. Moreover, the Weibull distribution was fitted to experimental results and the survival scale and shape parameters were calculated. The findings are analyzed on the basis of improving the efficiency of $V$. canescens as biocontrol agent against stored product pests.

\section{MATERIAL AND METHODS}

Full-grown larvae of the Mediterranean Flour Moth Ephestia kuehniella Zeller (Lepidoptera: Pyralidae) were used as hosts. The host species was reared in incubators at $25^{\circ} \mathrm{C}$ with a photoperiod of $16 \mathrm{~L}: 8 \mathrm{D}$ and $65 \pm 5 \%$ R.H. Cultures were maintained in clear plastic boxes $(17 \times 11 \times 5 \mathrm{~cm})$ containing $200-250 \mathrm{~g}$ of semolina with $250-300$ host eggs. This arrangement ensured that larvae had an excess of food throughout their larval life.

The original population of the parasitoid was collected in flourmills near Athens, Attiki. Venturia canescens was also reared in same type of plastic boxes as E. kuehniella. Approximately, $2004^{\text {th }}-5^{\text {th }}$ instar moth larvae from the stock culture were placed in each box together with 10 adult wasps. This procedure was repeated every 4 days. The boxes were left until the wasps emerged.

Effect of temperature, host presence and adult feeding on longevity

To segregate parasitoids for experiments, parasitoid pupae were removed from the culture, placed individually in Petri dishes and kept at $20^{\circ} \mathrm{C}$. Newly emerged adults were reared without access to food or were provided with honey ad libitum smeared on the inside of the dish, with or without access to hosts, according to the experimental design. A uniform size of

\footnotetext{
* Author for correspondence; present address: Technological Educational Institute of Kalamata, School of Agricultural Technology, Department of Crop Production, 24100 Antikalamos, Kalamata, Greece; e-mail: gstathas@teikal.gr
} 
wasp was achieved by selecting adults whose hind tibia length were between 1.85 and $1.95 \mathrm{~mm}$ long.

Adult longevity of cohorts of 35 honey-fed or starved individuals exposed to a range of constant temperatures $(15,20,25$ and $30^{\circ} \mathrm{C}$ ), with or without access to hosts, was measured. The daily supply of honey and hosts (50 mature L5 larvae of $E$. kuehniella) was achieved by the transferring of each experimental adult to a Petri dish identical with the initial one. Daily observations (every $8 \mathrm{~h}$ for cohorts at $30^{\circ} \mathrm{C}$ ) were made to determine whether the parasitoids were still alive.

\section{Effect of body size on longevity}

The effect of body size on adult longevity was investigated using 92 newly emerged adult wasps of various sizes. In order to obtain adults of different sizes they were collected daily from cultures of host larvae parasitized at the $2^{\text {nd }}$ up to the $5^{\text {th }}$ instar. In koinobiont parasitoids, which consume the entire host before pupation (like $V$. canescens) adult parasitoid size is often strongly correlated with host size (instar) at time of parasitism (Harvey \& Thompson, 1995; Harvey \& Vet, 1997; Hemerik \& Harvey, 1999) or there is a consistent relationship between host size at oviposition and death (Mackauer \& Sequeira, 1993). Thus, adults that emerge from hosts parasitized in different instars vary in body size. Adult wasps were fed on honey and kept isolated from hosts at $20^{\circ} \mathrm{C}$. After death the body size of experimental wasps was determined by measuring the length of a hind tibia under a calibrated stereomicroscope. Experimental adults of almost equal size were grouped so as to create a total of seven groups with hind tibial lengths of: $<1.76,1.77-1.83$, $1.84-1.89,1.90-1.95,1.96-2.01,2.02-2.09$ and $>2.1 \mathrm{~mm}$.

\section{Statistical analysis of experimental data}

Effect of body size on longevity

Data were submitted to an analysis of variance with $\alpha=0.05$. Means were separated using the Tukey-Kramer HSD Test (Sokal \& Rohlf, 1995). Statistical analysis was performed using the statistical package JMP v. 4.0.2 (SAS, 2000). In addition, for pairs of data between two variables correlation coefficients were calculated. The coefficients' were tested for departure from zero using two-tailed t-test with n-2 df (Sokal \& Rohlf, 1995).

Effect of temperature, host presence and adult feeding on longevity

Data were submitted to a 3-way ANOVA with $\alpha=0.05$ to determine whether the main effects and various interactions were significant. The main effects were a) temperature $(15,20$, 25 and $30^{\circ} \mathrm{C}$ ), b) presence or absence of food and c) presence or absence of hosts. The comparison of the means was performed as above.

\section{Weibull distribution}

The Weibull frequency distribution was used to describe the age specific survival of individuals in each regime. The proportion surviving at time $t$ is given by:

$$
S_{(t)}=e^{-(t / b)^{c}}, \mathrm{t}, \mathrm{b}, \mathrm{c}>0
$$

where $b$ and $c$ are the scale and shape parameters of the distribution, respectively. The value of the shape parameter $\mathrm{c}>1,=1$, and $<1$ correspond to Deevey's (1947) type I, II and III survivorship curves, respectively (Pinder et al., 1978). The estimation of these parameters was done using JMP statistical program (SAS, 2000). LT $_{50}$ values (the time interval after which the population of the parasitoid was reduced to half) were also calculated from the fitted Weibull curves. Furthermore, coefficients of non-linear regression $\left(\mathrm{R}^{2}\right)$ were calculated for each Weibull curve using a SPSS statistical program. The b and $c$ values of the cohorts of adults reared at different temperatures,

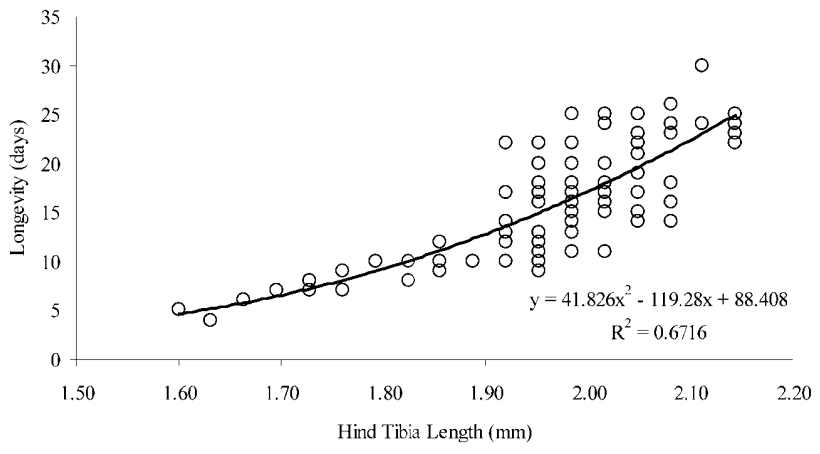

Fig. 1. Correlation between body size and longevity of honey-fed adults of $V$. canescens that did not have access to hosts ( $\mathrm{n}=92$ adults, temperature: $20^{\circ} \mathrm{C}$ ).

host and feeding regimes were compared using the tables of Thoman \& Bain (1969) and Thoman et al. (1969).

\section{RESULTS}

\section{Effect of body size}

Parasitoid longevity covaried significantly with adult wasp size $(\mathrm{n}=92, \mathrm{r}=0.80, \mathrm{P}<0.001$, Fig. 1$)$. The differences among adult groups were statistically significant (df $=6,85 ; \mathrm{F}=30.03 ; \mathrm{P}<0.0001$ ) (Fig. 2), with large adults (hind tibia length $>1.96 \mathrm{~mm}$ ) living considerably longer (mean $\approx 19.3$ days) than small adults (hind tibia length $<$ $1.89 \mathrm{~mm}$ ) (mean $\approx 8.1$ days), at $25^{\circ} \mathrm{C}$.

\section{Effect of temperature, feeding and host presence}

In all cases longevity decreased with increase in temperature (Table 1). The differences among different temperatures were statistically significant irrespective of feeding treatment and host presence: fed adults without hosts ( $\mathrm{df}=3,136 ; \mathrm{F}=146.55 ; \mathrm{P}<0.0001)$ and with hosts $(\mathrm{df}=3,136 ; \mathrm{F}=206.28 ; \mathrm{P}<0.0001)$, starved adults with hosts ( $\mathrm{df}=3,136 ; \mathrm{F}=199.21 ; \mathrm{P}<0.0001)$ and without hosts $(\mathrm{df}=3,136 ; \mathrm{F}=94.93 ; \mathrm{P}<0.0001)$. Differences between two successive temperatures were significant only between 15 and $25^{\circ} \mathrm{C}$ (Table 1).

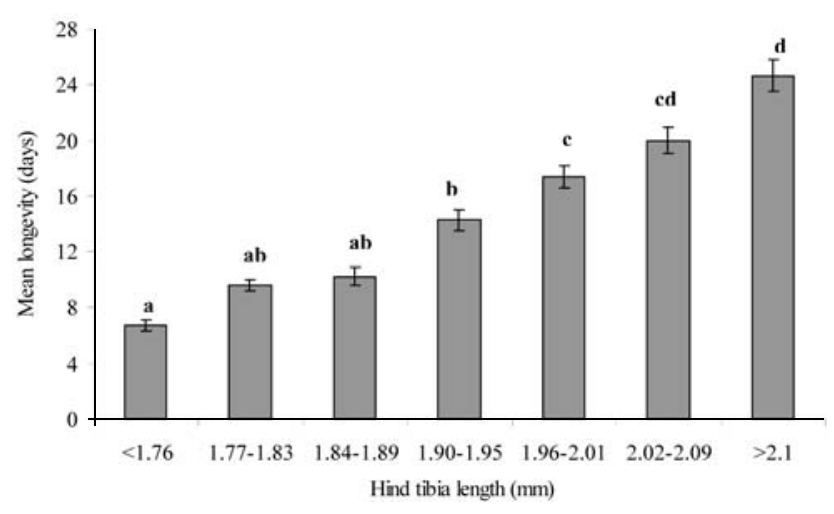

Fig. 2. Longevity of honey-fed adults of $V$. canescens of different body size that did not have access to hosts (Bars represent the standard error of the mean, numbers followed by the same letter are not significantly different (Tukey-Kramer HSD Test, a - 0.05), sample sizes: $\mathrm{n}_{<1.76}=12 ; \mathrm{n}_{1.77-1.83}=5 ; \mathrm{n}_{1.84-1.89}=4 ; \mathrm{n}_{1.90-1.95}$ $=24 ; \mathrm{n}_{1.96-2.01}=23 ; \mathrm{n}_{2.02-2.09}=18 ; \mathrm{n}_{>2.1}=6$, temperature $=20^{\circ} \mathrm{C}$ ). 
TABLE 1. Longevity in days (mean \pm S.E.) of honey-fed and starved adults of $V$. canescens with or without access to host at various constant temperatures ( $65 \pm 5 \%$ R.H., photoperiod: $16 \mathrm{~L}: 8 \mathrm{D}, \mathrm{n}=35$ adults).

\begin{tabular}{|c|c|c|c|c|}
\hline \multirow{2}{*}{ Temperature $\left({ }^{\circ} \mathrm{C}\right)$} & \multicolumn{2}{|c|}{ Honey-fed adults } & \multicolumn{2}{|c|}{ Starved adults } \\
\hline & without hosts & with hosts & without hosts & with hosts \\
\hline 15 & $\begin{array}{c}50.00 \pm 1.95 \mathrm{a}^{1} \mathrm{~A}^{2}+^{3} \\
{[24-71]}\end{array}$ & $\begin{array}{c}42.80 \pm 1.54 \mathrm{a}^{\mathrm{F}} \mathrm{A}+ \\
{[21-55]}\end{array}$ & $\begin{array}{c}17.46 \pm 1.01 \mathrm{bA}^{*} \\
{[9-29]}\end{array}$ & $\begin{array}{c}14.00 \pm 0.67 \mathrm{cA}^{*} \\
{[9-21]}\end{array}$ \\
\hline 20 & $\begin{array}{c}17.51 \pm 0.86 \mathrm{aB}+ \\
\quad[11-31]\end{array}$ & $\begin{array}{c}15.60 \pm 1.10 \mathrm{aB}+ \\
{[5-30]}\end{array}$ & $\begin{array}{c}9.40 \pm 0.61 \mathrm{bB} * \\
{[2-14]}\end{array}$ & $\begin{array}{c}5.26 \pm 0.39 \mathrm{cB}^{*} \\
{[2-9]}\end{array}$ \\
\hline 25 & $\begin{array}{c}8.00 \pm 0.35 \mathrm{aC}+ \\
{[5-13]}\end{array}$ & $\begin{array}{c}7.37 \pm 0.38 \mathrm{aC}+ \\
{[5-13]}\end{array}$ & $\begin{array}{c}4.60 \pm 0.36 \mathrm{bC} * \\
{[1-9]}\end{array}$ & $\begin{array}{c}2.19 \pm 0.23 \mathrm{cC}^{*} \\
{[1-6]}\end{array}$ \\
\hline 30 & $\begin{array}{c}5.71 \pm 0.34 \mathrm{aC}+ \\
{[3-10]}\end{array}$ & $\begin{array}{c}4.19 \pm 0.31 \mathrm{a}^{\mathrm{F}} \mathrm{C}+ \\
{[0.5-8]}\end{array}$ & $\begin{array}{c}1.94 \pm 0.15 \mathrm{bC} * \\
{[0.5-4]}\end{array}$ & $\begin{array}{c}1.29 \pm 0.11 \mathrm{cC} * \\
{[0.3-2.3]}\end{array}$ \\
\hline
\end{tabular}

[ ] - value range; ${ }^{1}$ - for each feeding treatment, values in rows followed by the same small letter are not significantly different; ${ }^{2}$ - values in columns followed by the same capital letter are not significantly different; ${ }^{3}$ - for each host treatment, values in rows followed by the same symbol $\left(+\right.$ or $\left.{ }^{*}\right)$ are not significantly different; ${ }^{\mathrm{F}}$ - differences were significant but small and biologically meaningless.

The longevity of honey-fed parasitoids maintained at the same temperature showed no dependence on access to hosts $\left(15^{\circ} \mathrm{C}: \mathrm{df}=1,68 ; \mathrm{F}=8.40, \mathrm{P}=0.0051,20^{\circ} \mathrm{C}: \mathrm{df}=\right.$ 1,$68 ; \mathrm{F}=1.88, \mathrm{P}=0.1752,25^{\circ} \mathrm{C}: \mathrm{df}=1,68 ; \mathrm{F}=1.47, \mathrm{P}$ $=0.2298$ and $30^{\circ} \mathrm{C}: \mathrm{df}=1,68 ; \mathrm{F}=10.90 ; \mathrm{P}=0.0015$; differences found at 15 and $30^{\circ} \mathrm{C}$ proved to be significant but were small and biologically meaningless). Starved wasps with no access to hosts lived significantly longer than those that had access to hosts $\left(15^{\circ} \mathrm{C}: \mathrm{df}=1,68 ; \mathrm{F}=\right.$ $8.15, \mathrm{P}=0.0057,20^{\circ} \mathrm{C}: \mathrm{df}=1,68 ; \mathrm{F}=32.57, \mathrm{P}<0.0001$, $25^{\circ} \mathrm{C}: \mathrm{df}=1,68 ; \mathrm{F}=31.54,<0.0001$ and $30^{\circ} \mathrm{C}: \mathrm{df}=1,68$; $\mathrm{F}=12.26 ; \mathrm{P}=0.0008)$ (Table 1$)$.

Host deprived wasps experienced $\sim 73-186 \%$ increase in longevity when they were supplied with honey $\left(15^{\circ} \mathrm{C}\right.$ : $\mathrm{df}=1,68 ; \mathrm{F}=219.99 ; \mathrm{P}<0.0001,20^{\circ} \mathrm{C}: \mathrm{df}=1,68 ; \mathrm{F}=$ $59.31 ; \mathrm{P}<0.0001,25^{\circ} \mathrm{C}: \mathrm{df}=1,68 ; \mathrm{F}=45.49 ; \mathrm{P}<$ 0.0001 and $30^{\circ} \mathrm{C}$ : $\mathrm{df}=1,68 ; \mathrm{F}=101.34 ; \mathrm{P}<0.0001$ ). The respective increase for ovipositing wasps was $\sim 196-236 \%\left(15^{\circ} \mathrm{C}: \mathrm{df}=1,68 ; \mathrm{F}=293.62 ; \mathrm{P}<0.0001\right.$, $20^{\circ} \mathrm{C}: \mathrm{df}=1,68 ; \mathrm{F}=78.14 ; \mathrm{P}<0.0001,25^{\circ} \mathrm{C}: \mathrm{df}=1,68$; $\mathrm{F}=134.62 ; \mathrm{P}<0.0001$ and $30^{\circ} \mathrm{C}: \mathrm{df}=1,68 ; \mathrm{F}=76.93 ; \mathrm{P}$ $<0.0001$ ) (Table 1).

A 3-way ANOVA revealed that the main effect of host presence and its interaction with temperature were insignificant, whereas all other main effects and interactions proved to be significant (Table 2).

\section{Weibull distribution}

The survival curves of adults of all cohorts are shown in Fig. 3. The proportion surviving at each time interval is presented, along with the fitted Weibull curve. Non-linear regression coefficient values $\left(\mathrm{R}^{2}\right)$ ranged between 0.85-0.99 (Table 3). The values of Weibull parameters

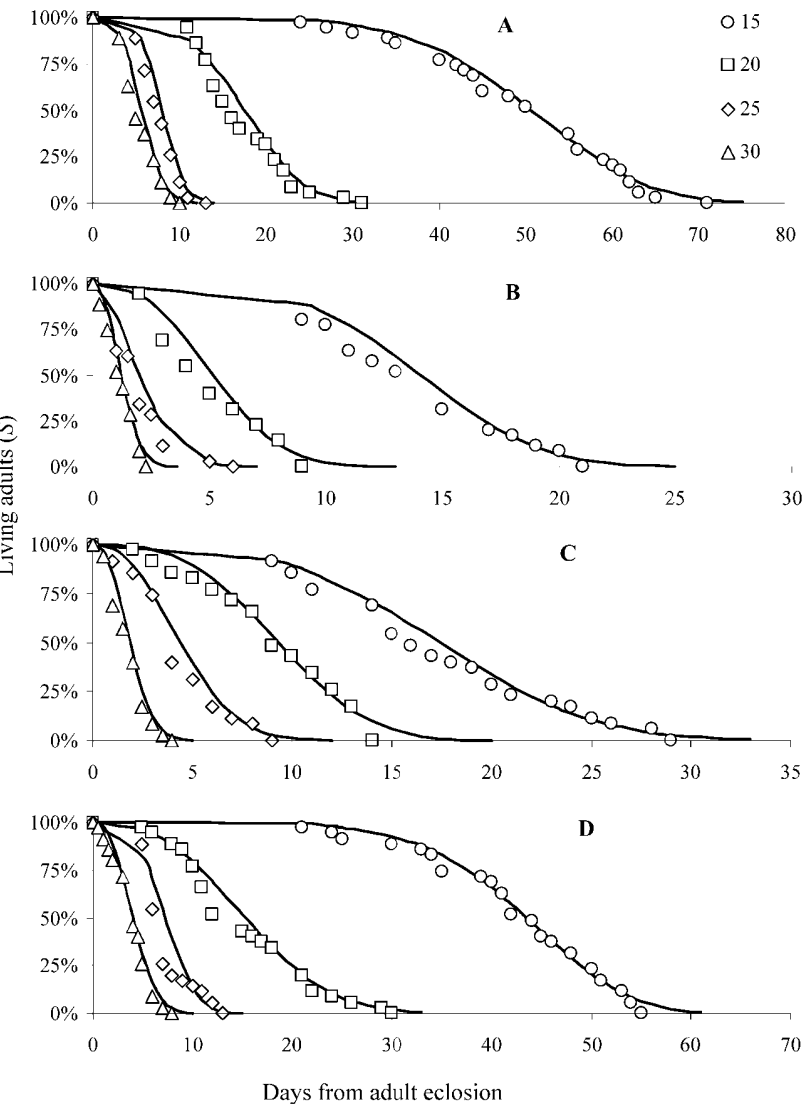

Fig. 3. Survival curves of adults of $V$. canescens with: A access to hosts; $\mathrm{B}$ - access to food; $\mathrm{C}$ - deprived of both food and hosts; D - access to both food and hosts, at a range of constant temperatures.

TABLE 2. Analysis of variance (3-way ANOVA) for main effects and interactions of temperature (T), access to food (F) and host presence $(\mathrm{H})$ on longevity of $V$. canescens $(\alpha=0.05$, error $\mathrm{df}=546)$.

\begin{tabular}{|c|c|c|c|c|c|c|c|}
\hline & \multicolumn{3}{|c|}{ Main effects } & \multicolumn{4}{|c|}{ Interactions } \\
\hline & $\mathrm{T}$ & $\mathrm{H}$ & $F$ & $\mathrm{~T} \times \mathrm{H}$ & $\mathrm{T} \times \mathrm{F}$ & $\mathrm{F} \times \mathrm{H}$ & $\mathrm{T} \times \mathrm{F} \times \mathrm{H}$ \\
\hline df & 3 & 1 & 1 & 3 & 3 & 1 & 3 \\
\hline $\mathrm{F}$ & 265.65 & 2.45 & 248.34 & 1.41 & 190.74 & 33.47 & 4.99 \\
\hline $\mathrm{P}$ & $<0.0001$ & 0.1178 & $<0.0001$ & 0.2377 & $<0.0001$ & $<0.0001$ & 0.0020 \\
\hline
\end{tabular}




\begin{tabular}{|c|c|c|c|c|c|c|}
\hline & & & \multicolumn{4}{|c|}{ Temperature $\left({ }^{\circ} \mathrm{C}\right)$} \\
\hline & & & 15 & 20 & 25 & 30 \\
\hline \multirow{14}{*}{$\begin{array}{l}\text { Honey-fed } \\
\text { adults }\end{array}$} & \multirow{7}{*}{$\begin{array}{c}\text { without } \\
\text { hosts }\end{array}$} & $\mathrm{n}$ & 35 & 35 & 35 & 35 \\
\hline & & $\mathrm{b}$ & $54.408 \mathrm{a}$ & $19.394 b$ & $8.789 \mathrm{c}$ & $6.405 \mathrm{c}$ \\
\hline & & $\mathrm{c}$ & $5.303 \mathrm{a}$ & $3.641 \mathrm{a}$ & $4.287 \mathrm{a}$ & $3.130 \mathrm{a}$ \\
\hline & & $\mathrm{LT}_{50 \mathrm{~W}}$ & 50.77 & 17.53 & 8.06 & 5.69 \\
\hline & & $\mathrm{LT}_{500}$ & $50-55$ & $15-16$ & $7-8$ & $4-5$ \\
\hline & & Type & I & I & I & I \\
\hline & & $\mathrm{R}^{2}$ & 0.98 & 0.94 & 0.95 & 0.93 \\
\hline & \multirow{7}{*}{ with hosts } & $\mathrm{n}$ & 35 & 35 & 35 & 35 \\
\hline & & $\mathrm{b}$ & $46.302 \mathrm{a}$ & $17.614 b$ & $8.197 \mathrm{c}$ & $4.700 \mathrm{c}$ \\
\hline & & $\mathrm{c}$ & $5.944 \mathrm{a}$ & $2.626 \mathrm{a}$ & $3.306 \mathrm{a}$ & $2.451 \mathrm{a}$ \\
\hline & & $\mathrm{LT}_{50 \mathrm{~W}}$ & 43.53 & 15.32 & 7.33 & 4.04 \\
\hline & & $\mathrm{LT}_{500}$ & $42-44$ & $12-15$ & $6-7$ & $3-4$ \\
\hline & & Type & I & I & I & I \\
\hline & & $\mathrm{R}^{2}$ & 0.98 & 0.97 & 0.85 & 0.98 \\
\hline \multirow{14}{*}{$\begin{array}{c}\text { Starved } \\
\text { adults }\end{array}$} & \multirow{7}{*}{$\begin{array}{l}\text { without } \\
\text { hosts }\end{array}$} & $\mathrm{n}$ & 35 & 35 & 35 & 35 \\
\hline & & $\mathrm{b}$ & $19.518 \mathrm{a}$ & $10.535 b$ & $5.190 \mathrm{c}$ & $2.198 \mathrm{c}$ \\
\hline & & $\mathrm{c}$ & $3.246 \mathrm{a}$ & $2.972 \mathrm{a}$ & $2.290 \mathrm{a}$ & $2.347 \mathrm{a}$ \\
\hline & & $\mathrm{LT}_{50 \mathrm{~W}}$ & 17.42 & 9.31 & 4.42 & 1.88 \\
\hline & & $\mathrm{LT}_{500}$ & $15-16$ & $8-9$ & $3-4$ & $1.5-2$ \\
\hline & & Type & I & I & I & I \\
\hline & & $\mathrm{R}^{2}$ & 0.96 & 0.96 & 0.96 & 0.96 \\
\hline & \multirow{7}{*}{ with hosts } & $\mathrm{n}$ & 35 & 35 & 35 & 35 \\
\hline & & $\mathrm{b}$ & $15.485 \mathrm{a}$ & $5.950 \mathrm{~b}$ & $2.477 \mathrm{c}$ & $1.452 \mathrm{c}$ \\
\hline & & c & $3.945 \mathrm{a}$ & $2.538 \mathrm{a}$ & $1.789 \mathrm{a}$ & $2.154 \mathrm{a}$ \\
\hline & & $\mathrm{LT}_{50 \mathrm{~W}}$ & 14.11 & 5.15 & 2.02 & 1.22 \\
\hline & & $\mathrm{LT}_{500}$ & $13-15$ & $4-5$ & $1.5-2$ & $1-1.3$ \\
\hline & & Type & I & I & I & I \\
\hline & & $\mathrm{R}^{2}$ & 0.94 & 0.93 & 0.89 & 0.95 \\
\hline
\end{tabular}

Values of $\mathrm{b}$ and $\mathrm{c}$ of the same feeding treatment and host presence followed by the same letter are not significantly different [Tables of Thoman \& Bain (1969) and Thoman et al. (1969), a = 0.05]; $\mathrm{n}-$ sample size; $\mathrm{LT}_{50 \mathrm{~W}}-\mathrm{LT}_{50}$ value calculated using the Weibull equation; $\mathrm{LT}_{500}-\mathrm{LT}_{50}$ value range estimated from experimental data; $\mathrm{R}^{2}$ - coefficient of non linear regression.

(b,c) and $\mathrm{LT}_{50}$ are included in Table 3. The shape parameter (c) was always significantly $>1$. Both feeding and access to host did not influence the $c$ value significantly.

\section{DISCUSSION}

Several authors have proposed that intra-specific variation in parasitoid life histories can be classified according to their mode of development: ectoparasitoids and idiobionts have one suite of traits, and endoparasitoids and koinobionts (such as $V$. canescens) another. Longevity is strongly correlated with mode of development given that shorter adult lifespan is associated with endoparasitism and/or koinobiosis (Mayhew \& Blackburn, 1999).

\section{Effect of body size}

Body size influences many ecological and biological parameters of parasitoids, including longevity (e.g. Godfray, 1994; Jervis \& Copland, 1996). This was verified for $V$. canescens as the large wasps (hind tibia length $>$ $1.96 \mathrm{~mm}$ ) lived significantly longer than the small ones (hind tibia length $<1.89 \mathrm{~mm}$ ). A positive correlation between body size and longevity is recorded for adults of $V$. canescens reared on Plodia interpunctella (Hübner) (Lepidoptera: Pyralidae) (Fletcher et al., 1994; Harvey et al., 1994), as well as for other parasitoids of stored product pests, like Lariophagus distinguendus Förster
(Hymenoptera: Pteromalidae) (Bellows, 1985), Trichogramma evanescens Westwood (Hymenoptera: Trichogrammatidae) (Waage \& $\mathrm{Ng}, 1984$ ) and Goniozus nephantidis (Muesebeck) (Hymenoptera: Bethyidae) (Hardy et al., 1992).

In contrast, Blackburn argued that very few life history traits correlate with parasitoids' body size, emphasizing that longevity was not one of them (Blackburn, 1991).

\section{Effect of temperature}

There is an optimum temperature range for every insect species outside of which survival is severely reduced (Jackson, 1966; Krishnamoorthy, 1989). Longevity of most insect species decreases with increasing temperature within the optimum range. This phenomenon was recorded for $V$. canescens during the present study. Adults maintained at $15^{\circ} \mathrm{C}$ lived much longer than wasps kept at other temperatures under all food regimes. Correspondingly, reduced longevity was recorded in adults maintained at $30^{\circ} \mathrm{C}$.

Corbet \& Rotheram (1965), report that fed $V$. canescens adults lived $20-25$ days at $25^{\circ} \mathrm{C}$. In the present study it ranged between 11-31 days. When adults supplied with food kept in fluctuating temperatures of $17.6-22^{\circ} \mathrm{C}$ and $15.4-16.9^{\circ} \mathrm{C}$, they live for $17-28$ and $38-59$ days, respectively (Shikrenov, 1970). However, these results cannot be compared with those of the present study as they were 
not recorded at constant temperatures. Fletcher et al. (1994), observed that starved adults of $V$. canescens did not live longer than 3 days at $25^{\circ} \mathrm{C}$ ( 9 days in the present study) and half the population did not survive to the $2^{\text {nd }}$ day (3-4 days in the present study).

Kurstak (1966) reports that wasps fed on sugar solution lived 43 days at $15^{\circ} \mathrm{C}, 22$ days at $20^{\circ} \mathrm{C}$ and 15 days at $25^{\circ} \mathrm{C}$, and starved adults for 4,8 and 17 days, respectively. Our results agree with those of Kurstak only for starved adults $\left(17.46\right.$ days at $15^{\circ} \mathrm{C}, 9.40$ days at $20^{\circ} \mathrm{C}$ and 4.60 days at $25^{\circ} \mathrm{C}$ ). In contrast, our results for fed wasps differ from those of Kurstak. This can be attributed to the different types of food (sugar solution - honey) in these two studies. Food type is known to influence parasitoid longevity (Jervis \& Copland, 1996; Jervis et al., 1996; Schmäle et al., 2001; Wäckers, 2001).

\section{Effect of feeding}

Fed adults lived significantly longer than starved conspecifics at all temperatures, irrespective of whether hosts were available or not. Many studies have shown that parasitoids supplied with carbohydrate-rich foods such as honey, sugar, honeydew, nectar etc., lived longer than adults that were either starved or given only water (Wäckers, 1996; McDougall \& Mills, 1997; Wäckers et al., 1998; Schmäle et al., 2001). The importance of adult nutrition for $V$. canescens was first suggested by Beling (1932), when she observed newly emerged wasps leaving the habitat and host environment soon after emergence, and that the "returning" wasps had nectar droplets on their mouthparts.

In the present study supplying honey significantly increased the longevity of $V$. canescens adults in all cases. Similar observations are recorded in earlier studies (Beling, 1932; Ahmad, 1936; Frilli, 1965; Kurstak, 1966; Shikrenov, 1970; Matsumoto, 1974). Starved and host deprived adults lived for 3.5 days at $23^{\circ} \mathrm{C}$ while those that were fed lived as long as 40 days (Ahmad, 1936). Furthermore, Beling (1932) records that food type has a significant effect on longevity, with adults fed a sugar solution living up to 57 days and honey up to 72 days.

The same relation between feeding and longevity is recorded for parasitoids with completely different biology such as Aphytis melinus DeBach (Hymenoptera: Aphelinidae) (Heimpel et al., 1997), Trichogramma platneri Nagarkatti (Hymenoptera: Trichogrammatidae) (McDougall \& Mills, 1997), Catolaccus grandis (Burks) (Hymenoptera: Pteromalidae) (Morales-Ramos \& Cate, 1992), and others.

The effect of feeding depends on temperature and availability of hosts and interactions between these factors (Table 2). This can be attributed to the fact that the time available for feeding is reduced either when temperature declines (due to inactivity) or time-consuming parasitism occurs. Consequently, the wasp is undernourished in both cases.

Adult feeding can have a strong effect on parasitoid fitness measured in terms of longevity, lifetime fecundity, survival, searching efficiency, overall activity etc. (Godfray, 1994; Jervis \& Copland, 1996; Jervis et al., 1996;
Jervis \& Kidd, 1999). This is the same not only for $V$. canescens (Ahmad, 1936; Matsumoto, 1974; Harvey et al., 2001; Eliopoulos, 2003) but also for many parasitoids of stored product pests (van Huis et al., 1990; Wäckers, 1996; Wäckers et al., 1998; Schmäle et al., 2001).

The above plus the fact that a lack of suitable carbohydrate food sources in man-made ecosystems has long been suspected to be an important cause of failure of many biological control programs (Wolcott, 1942; Hocking, 1967), justifies the use of food supplements at release sites to augment the efficacy of released parasitoids and other biocontrol agents, especially in storage facilities (Schöller et al., 1997; Wäckers et al., 1998). The use of food supplements could greatly improve the efficacy of biological control of stored product pests.

\section{Effect of host presence}

Providing hosts resulted in the parasitoid having a short life at all temperatures, regardless of food supply. Beling (1932), attributes this to energy consumption for parasitism needs. Reduced longevity associated with parasitism is recorded for many non-host feeding parasitoids (Jervis et al., 1996) and is recorded for $V$. canescens by Ahmad (1936) (40 to 20 days) and Matsumoto (1974) (35 to 22 days).

Host deprivation also results in a longer adult life in Gryon pennsulvanicum (Ashmead) (Hymenoptera: Scelionidae) (Vogt \& Nechols, 1993), Diadromus subtilicornis (Gravenhorst) (Hymenoptera: Ichneumonidae) (Tran \& Takasu, 2000), Telenomus isis (Polaszek) (Hymenoptera: Scelionidae) (Chabi-Olaye et al., 2001).

However, temperature and feeding had a greater effect on adult longevity than availability of hosts (Table 2). Irrespective of treatment, wasps supplied with food and deprived of hosts did not live significantly longer than adults with food and hosts. Similar results are presented by Harvey et al. (2001).

Longevity of koinobiont endoparasitoids, which are mostly $r$-strategists, appears to be correlated with host availability (Blackburn, 1991). According to some interpretations of the theory of the $r-k$ continuum, small species should be $r$-selected, with short generation times and high reproductive capacities, while large species should be $k$-selected, with long life spans and low rates of reproduction (Pianka, 1970; Blackburn, 1991). Venturia canescens is one of the biggest parasitoids, has a moderate life span and a copious egg production and seems to be a classic example of a compromise between $r$ and $k$ selection (J.F. Harvey, pers. commun.).

However, it should be mentioned that there is no convincing evidence of a trade-off between reproduction and life expectancy given that host density has no effect upon adult survival in koinobionts (Jervis \& Copland, 1996).

\section{Weibull distribution}

The Weibull distribution is an effective way of representing longevity data and describing survival curves. It enables the shape and scale of different survival curves to be compared statistically and provides valuable informa- 
tion that is lost if results are presented in the form of a mean with a standard deviation.

High values for the non-linear regression coefficients $\left(\mathrm{R}^{2}: 0.85-0.99\right)$ indicate that the distribution very satisfactorily described the data. The $\mathrm{LT}_{50}$ values calculated using the distribution equation $\left(\mathrm{LT}_{50 \mathrm{w}}\right)$ fall within the range of observed values $\left(\mathrm{LT}_{500}\right)$ or are slightly higher (Table 3 ).

As Jervis \& Copland (1996) note longevity data are best presented as cohort survival curves so that biologically meaningful comparisons between treatments can be made. Value of the shape parameter (c) was always significantly $>1$ irrespective of temperature, food and host presence, indicating that the survival curve of $V$. canescens is of Type I, in which the risk of death increases with age. Estimates of $c$ for different cohorts of $V$. canescens adults indicate that all the survivorship curves are similarly shaped.

ACKNOWLEDGEMENTS. The senior author would like to express his gratitude to $\mathrm{C}$. Buchelos for his guidance during the course of the present study and thanks J. Harvey for valuable discussions on Venturia canescens.

\section{REFERENCES}

Aнmad T. 1936: The influence of ecological factors on the Mediterranean Flour Moth, Ephestia kühniella and its parasite Nemeritis canescens. J. Anim. Ecol. 5: 67-93.

Beling I. 1932: On the biology of Nemeritis canescens. I. Breeding experiences and ecological observations. Z. Angew. Entomol. 19: 223-249 (in German, English abstr.).

Bellows T.S. 1985: Effects of host age and host availability on developmental period, adult size, sex ratio, longevity and fecundity in Lariophagus distinguendus Förster (Hymenoptera: Pteromalidae). Res. Pop. Ecol. 27: 55-64.

BLACKBURN T.M. 1991: A comparative examination of life span and fecundity in parasitoid hymenoptera. J. Anim. Ecol. 60: $151-164$.

CANDURA G.S. 1928: A contribution to the knowledge of the moth infesting foodstuffs, Ephestia kuehniella Zeller, and of its parasite, Nemeritis canescens, Gravenhorst. Boll. Lab. Zool. Portici 21: 149-214.

Chabi-Olaye A., Schulthess F., Poehling H.M. \& BorgeMEISTER C. 2001: Factors affecting the biology of Telenomus isis (Polaszek) (Hymenoptera: Scelionidae), an egg parasitoid of cereal stem borers in West Africa. Biol. Control 21: 44-54.

Corbet S.A. \& Rotheram S. 1965: The life history of the ichneumonid Nemeritis (Devorgilla) canescens (Gravenhorst) as a parasite of the Mediterranean flour moth, Ephestia (Anagasta) kuehniella Zeller, under laboratory conditions. Proc. $R$. Entomol. Soc. Lond. (A) 40: 67-72.

DeEveY E.S. 1947: Life tables for natural populations of animals. Quart. Rev. Biol. 22: 283-314.

Eliopoulos P.A. 2003: Study of the Parasitoid Venturia canescens (Hymenoptera: Ichneumonidae) as a Biocontrol Agent Against Lepidopterous Pests of Stored Products. Ph.D. Thesis, Agricultural University of Athens, 181 pp. (in Greek, English abstr.).

Fletcher J.P., Hughes J.P. \& Harvey I.F. 1994: Life expectancy and egg load affect oviposition decisions of a solitary parasitoid. Proc. R. Soc. Lond. (B, Biol. Sci.) 258: 163-167.

FriLli F. 1965: Studies on the Ichneumonid Hymenoptera. I. Devorgilla canescens (Grav.). Entomologica 1: 119-209 (in Italian, English abstr.).
Godfray H.C.J. 1994: Parasitoids - Behavioral and Evolutionary Ecology. Princeton Univ. Press, Princeton, NJ, 473 pp.

Hardy I.C.W., Griffiths N.T. \& Godfray H.C.J. 1992: Clutch size in a parasitoid wasp: a manipulation experiment. J. Anim. Ecol. 61: 121-129.

HARVEY J.A. \& ThOMPSON D.J. 1995: Host behaviour and its influence on foraging and acceptance by the solitary parasitoid wasp, Venturia canescens (Hymenoptera: Ichneumonidae). Entomophaga 40: 193-210.

HaRveY J.A. \& Vet L.E.M. 1997: Venturia canescens parasitizing Galleria mellonella and Anagasta kuehniella: differing suitability of two hosts with highly variable growth potential. Entomol. Exp. Appl. 84: 93-100.

Harvey J.A., Harvey I.F. \& Thompson D.J. 1994: Flexible larval growth allows use of a range of host sizes by a parasitoid wasp. Ecology 75: 1420-1428.

Harvey J.A., Harvey I.F. \& Thompson D.J. 2001: Lifetime reproductive success in the solitary endoparasitoid, Venturia canescens. J. Insect Behav. 14: 573-593.

Heimpel G.E., Rosenheim J.A. \& Kattari D. 1997: Adult feeding and lifetime reproductive success in the parasitoid Aphytis melinus. Entomol. Exp. Appl. 83: 305-315.

HemeriK L. \& Harvey J.A. 1999: Flexible larval development and the timing of destructive feeding by a solitary parasitoid: an optimal foraging problem in evolutionary perspective. Ecol. Entomol. 24: 308-315.

HockING H. 1967: The influence of food on longevity and oviposition by Rhyssa persuasoria (L.) (Hymenoptera: Ichneumonidae). J. Austr. Entomol. Soc. 6: 217-223.

Huis van A., KaAshoek N.K. \& Maes H.M. 1990: Biological control of Bruchids (Col.: Bruchidae) in stored pulses by using egg parasitoids of the genus Uscana (Hym.: Trichogrammatidae): a review. In Fleurat-Lassard F. \& Ducom P. (eds): Proceedings of $5^{\text {th }}$ International Working Conference on Stored Product Protection, Bordeaux, France, pp. 99-108.

JACKSON D.J. 1966: Observations on the biology of Caraphractus cinctus Walker (Hymenoptera: Mymaridae), a parasitoid of the eggs of Dytiscidae (Coleoptera). III. The adult life and sex ratio. Trans. R. Entomol. Soc. Lond. 118: 23-49.

Jervis M.A. \& Copland M.J.W. 1996: The life cycle. In Jervis M.A. \& Kidd N. (eds): Insect Natural Enemies - Practical Approaches to their Study and Evaluation. Chapman and Hall, London, pp. 63-161.

JeRVIS M.A. \& KIDD N.A.C. 1999: Parasitoid adult nutritional ecology: implications for biological control. In Hawkins B.A. \& Cornell H.V. (eds): Theoretical Approaches to Biological Control. Cambridge University Press, Cambridge, pp. 131-151.

Jervis M.A., Kidd N.A.C. \& HeImpel G.E. 1996: Parasitoid adult feeding behaviour and biocontrol - a review. Biocontr. News Inform. 17: 11-26.

KRISHNAMOORTHY A. 1989: Effect of cold storage on the emergence and survival of the adult exotic parasitoid, Leptomastix dactylopii How. (Hym., Encyrtidae). Entomon 14: 313-318.

KURSTAK E.S. 1966: The role of Devorgilla canescens in infection by B. thuringiensis in E. kühniella - First Part. Ann. Epiphyt. 17: 335-383 (in French, English abstr.).

Mackauer M. \& Sequeira R. 1993: Patterns of development in insect parasites. In Beckage, N.E., Thompson S.N. \& Frederici B.A. (eds): Parasites and Pathogens of Insects. Vol. 1. Academic Press, London, pp. 1-23.

Матsumoto B.M. 1974: On the adult longevity of the entomophagous parasite, Venturia canescens (Hymenoptera: Ichneumonidae). Entomophaga 19: 325-329. 
Mayhew P.J. \& Blackburn T.M. 1999: Does development mode organize life-history traits in the parasitoid hymenoptera? J. Anim. Ecol. 68: 906-916.

McDougall S.J. \& Mills N.J. 1997: The influence of hosts, temperature and food sources on the longevity of Trichogramma platneri. Entomol. Exp. Appl. 83: 195-203.

Morales-Ramos J.A. \& CATE J.R. 1992: Rate of increase and adult longevity of Catolaccus grandis (Burks) (Hymenoptera: Pteromalidae) in the laboratory at four temperatures. Environ. Entomol. 21: 620-627.

PianKa E.R. 1970: On $r$ and $k$ selection. Am. Nat. 104: 592-596.

Pinder J.E., Wiener J.G. \& Smith M.H. 1978: The Weibull distribution: a new method of summarizing survivorship data. Ecology 59: 175-179.

Salt G. 1975: The fate of an internal parasitoid, Nemeritis canescens, in a variety of insects. Trans. R. Entomol. Soc. Lond. 127: 141-461.

Salt G. 1976: The hosts of Nemeritis canescens, a problem in the host specificity of insect parasitoids. Ecol. Entomol. 1: 63-67.

SAS Institute. 2000: JMP, User's Guide, Version 4. SAS Institute Inc., Cary, N.C., 280 pp.

Schmäle I., Wackers F.L., Cardona C. \& Dorn S. 2001: Control potential of three hymenopteran parasitoid species against the bean weevil in stored beans: The effect of adult parasitoid nutrition on longevity and progeny production. Biol. Control 21: 134-139.

Schöller M., Prozell S., Al-Kirshi A.G. \& Reichmuth C. 1997: Towards biological control as a major component of integrated pest management in stored product protection. $J$. Stored Prod. Res. 33: 81-97.

ShIKRENOv D. 1970: The morphological and biological characteristics of Nemeritis canescens Grav., a parasite of Ephestia kuehniella Zell. Rast. Zash. 18: 22-24.

Sokal R.R. \& Rohlf F.J. 1995: Biometry - The Principles and Practice of Statistics in Biological Research. 3rd ed. W.H. Freeman, New York, 887 pp.
Thoman D.R. \& Bain L.J. 1969: Two sample tests in the Weibull distribution. Technometrics 11: 805-815.

Thoman D.R., Bain L.J. \& Antle C.E. 1969: Inferences on the parameters of the Weibull distribution. Technometrics 11: 445-460.

Tingle C.C.D. \& Copland M.J.W. 1989: Progeny production and adult longevity of the mealybug parasitoids Anagyrus pseudococci, Leptomastix dactylopii, and Leptomastidea abnormis (Hym.: Encyrtidae) in relation to temperature. Entomophaga 34: 111-120.

Tran T.V. \& TAKasu K. 2000: Life history of the pupal parasitoid Diadromus subtilicornis (Gravenhorst) (Hymenoptera: Ichneumonidae) as influenced by temperature, photoperiod, and availability of food and hosts. Entomol. Sci. 3: 255-264.

Vogt E.A. \& Nechols J.R. 1993: The influence of host deprivation and host source on the reproductive biology and longevity of the squash bug egg parasitoid Gryon pennsylvanicum (Ashmead) (Hymenoptera: Scelionidae). Biol. Control 3: 148-154.

WAAGe J.K. \& NG S-M. 1984: The reproductive strategy of a parasitic wasp. I. Optimal progeny and sex allocation in Trichogramma evanescens. J. Anim. Ecol. 53: 401-416.

WÄCKERS F. 1996: Can food provision increase the efficacy of biological control in storage systems? Proceedings of $20^{\text {th }}$ International Congress of Entomology. Firenze, Italy, 25-31 August 1996. p. 551.

WÄCKERS F.L. 2001: A comparison of nectar- and honeydew sugars with respect to their utilization by the hymenopteran parasitoid Cotesia glomerata. J. Insect Physiol. 47: 1077-1084.

Wäckers F.L., Schmäle K., Cardona C.M. \& Dorn S. 1998: The effect of food supplements on the longevity of the bean weavil parasitoids Anisopteromalus calandrae and Heterospilus prosopidis. IOBC/WPRS Bull. 21: 75-82.

WolcotT G.N. 1942: The requirements of parasitoids for more than hosts. Science 96: 317-318.

Received August 16, 2004; revised and accepted February 21, 2005 